\title{
SUPERVISI KEPALA SEKOLAH TERHADAP GURU DI SMK LPMD ADOW KECAMATAN PINOLOSIAN TENGAH KABUPATEN BOLAANG MONGONDOW SELATAN
}

\author{
Muliadi Mokodompit ${ }^{1}$ \\ ${ }^{1}$ Universitas Negeri Manado, Manado, Indonesia \\ e-mail: muliadi.mokodompit@yahoo.com
}

DOI: 10.35719/leaderia.v2i1.59

\begin{abstract}
Principal's supervision is part of efforts to ensure the quality of academic activities. Through the supervision the principal can direct teachers to improve the quality of learning in schools. This study aims to: "analyze the implementation of Principal Supervision of Teachers at SMK LPMD Adow, Central Pinolosian District, South Bolaang Mongondow Regency". This research is a qualitative descriptive form with a field research approach. Research informants were teachers of SMK LPMD Adow Pinolosian Tengah, cocnsists of 10 teachers. The data were collected using interview and documentation techniques. The results showed that the implementation of the Principal's Supervision was carried out in a planned, organized and periodic manner. The supervision stage begins with forming a supervision team, then the team formulates supervision objectives, supervision objectives, and makes supervision instruments. Supervision of the Principal of SMK LPMD Adow uses a persuasive approach, namely prioritizing feelings and maintaining harmonization. Thus, Principal Supervision at SMK LPMD Adow improves teacher teaching quality and teacher motivation in developing teaching knowledge and skills. In conclusion, that Principal's Supervision increases teacher motivation in improving teacher knowledge and skills comperehensively, so that it has an impact on the teaching quality of teachers in the classroom.
\end{abstract}

Keywords: Supervision, Academic, Motivation to Teach a Teacher, Quality Of Learning

\section{ABSTRAK}

Supervisi Kepala Sekolah merupakan bagian dari upaya menjamin mutu kegiatan akademik. Melalui supervisi kepala sekolah dapat mengarahkan guru untuk meningkatkan kualitas pembelajaran di sekolah. Penelitian ini bertujuan untuk: "menganalisis pelaksanaan Supervisi Kepala Sekolah terhadap Guru di SMK LPMD Adow Kecamatan Pinolosian Tengah, Kabupaten Bolaang Mongondow Selatan”. Penelitian ini termasuk jenis deskriptif kualitatif dengan pendekatan field research. Informan penelitian adalah Guru-Guru SMK LPMD Adow Pinolosian Tengah yang berjumlah 10 orang. Data dikumpulkan menggunakan teknik wawancara dan 
dokumentasi. Hasil penelitian menunjukkan bahwa pelaksanaan Supervisi Kepala Sekolah dilakukan secara terencana, terorganisisr dan berkala. Tahapan supervisi dimulai dengan pembentuk tim supervisi, kemudian tim merumuskan tujuan supervisi, sasaran supervisi, dan membuat instrumen supervisi. Supervisi Kepala Sekolah SMK LPMD Adow menggunnakan pendekatan persuasif, yaitu mengutamakan perasaan dan menjaga harmonisasi. Dengan demikian, Supervisi Kepala Sekolah di SMK LPMD Adow meningkatkan kualitas mengajar Guru dan motivasi guru dalam mengembangkan pengetahuan dan keterampilan mengajar. Sebagai kesimpulan, bahwa Supervisi Kepala Sekolah meningkatkan motivasi guru dalam meningkatkan pengetahuan dan keterampilan guru secara berkelanjutan, sehingga berdampak pada kualitas mengajar Guru di Kelas.

KataKunci: Supervisi, Akademik, Motivasi Mengajar Guru, Kualitas Pembelajaran

\section{PENDAHULUAN}

Guru memiliki peran penting dalam pengembangan Pendidikan, sebagaimana dikemukakan oleh Surasni (2018) bahwa: Qualitles to expect in a good change manager: 1) They know what they are trying to achieve, 2) They explain it clearly to others. 3) They can back their desires up with a practical plan of action, 4) They can present the changes as personally rewarding for a lot of teachers and pupils. Pemikiran Surasni tersebut meletakkan Peran penting guru pada kompetensi Guru (pedagogis, kepribadian, sosial, dan keprofesionalan) yang menunjang tercapainya tujuan Pendidikan.

Supervisi merupakan tugas kepemimpinan Kepala Sekolah dalam hal mewujudkan visi, misi dan tujuan pendidikan yang sudah disepakati bersama. Kepala Sekolah sebagai pemimpin menjadi penunjuk jalan kebaikan bagi jama'ahnya, dan membimbing mereka kepada suatu kemaslahatan (AsSuwaidan \& F. U. Basyarahil, 2009), sehingga semua jama'ahnya (Guru dan personel sekolah yang dipimpinnya) dapat berjalan sesuai peraturan dan mekanisme yang berlaku. Pelaksanaan supervisi ini akan mewujudkan keteraturan dan ketertiban bagi kehidupan organisasi dan umat di Sekolah/Madrasah.

Indikator supervisi akademik yang tertulis dalam Peraturan Menteri Pendidikan Nasional Republik Indonesia No 13 tahun 2007, tentang Standar Kompetensi supervisi akademik dijabarkan sebagai berikut: 1) Merencanakan program supervisi akademik dalam rangka peningkatan profesional Guru; 2) Melaksanakan supervisi akademik terhadap Guru dengan menggunakan pendekatan dan teknik-teknik supervisi; 3) Menindaklanjuti hasil supervisi akademik terhadap Guru dalam rangka mengelola profesionalisme Guru. Supervisi kepala sekolah akan memberikan dampak positif bagi guru. Sarifudin (2019), dalam penelitiannya menemukan bahwa kegiatan supervisi sangat berguna untuk memacu kinerja Guru dalam mengajar di kelas sehingga berimbas kepada prestasi belajar siswa. 
Studi ini dilakasanakan di Sekolah Menegah Kejuruan (SMK) LPMD Adow Kecamatan Pinolosian Kabupaten Bolaang Mongondow Selatan. Studi ini didasarkan pada kondisi mengajar Guru SMK LPMD Adow sangat rendah, seperti persiapan perangkat pembelajaran yang kurang baik, penguasaan metode pembelajaran masih standar, dan inovasi guru dalam pengembangan model pembelajaran berbasis teknologi informasi masih rendah. Jika hal ini terjadi secara terus menerus maka akan menyebakan kualitas mengajar Guru semakin menurun.

Berdasarkan research gap dan factual gap mengenai supervisi Kepala Sekolah dalam meningkatkan kinerja Guru, maka penelitian ini bertujuan untuk menganalisis Supervisi Kepala Sekolah di SMK LPMD Adow Kecamatan Pinolosian Tengah Kabupaten Bolaang Mongondow Selatan.

\section{METODE}

Jenis penelitian ini adalah deskriptif kualitatif dengan pendekatan studi lapangan (Nasution, 2006), yaitu mendeskripsikan pelaksanaan Supervisi Kepala Sekolah terhadap Guru SMK LPMD Adow Kecamatan Pinolosian Tengah Bolaaang Mongondow Selatan menggunakan analisis kualitatif. Penelitian ini menggunakan dua jenis data, yakni data primer dan data sekunder. Data primer merupakan data yang bersumber dari informan, terutama Kepala Sekolah dan Guru. Sedangkan data sekunder merupakan data penunjang berupa tulisan seperti profil Sekolah, visi-misi, tujuan sekolah dan gambar fisik sekolah. Data sekunder dalam penelitian ini bersumber langsung dari Sekolah SMK LPMD Adow Kecamatan Pinolosian Tengah Kabupaten Bolaang Mongondow Selatan.

Instrumen penelitian adalah alat yang digunakan peneliti dalam meneliti obyek yang telah ditetapkan. Instrumen dalam penelitian kualitatif deskriptif, adalah peneliti sendiri yang disebut sebagai Key informan yang harus terjun lansung secara aktif dalam melakukan proses wawancara (Usman dan P. S. Akbar, 2000). Oleh karena itu, untuk memperoleh data lapangan secara terarah, akurat dan mendalam, maka peneliti menggunakan pedoman wawancara dan alat bantu perekam taperecorder.

Teknik pengumpulan data yang dilakukan di dalam penelitian ini menggunakan teknik observasi, wawancara mendalam, dan analisis dokumen. Wawancara mendalam merupakan cara pengumpulan data yang berkaitan dengan permasalahan penelitian melalui kegiatan temu muka yang dilakukan peneliti terhadap subjek penelitian (informan). Pertanyaan yang diajukan berupa pertanyaan terbuka yang tidak berstruktur tetapi terpusat pada satu pokok bahasan.

Analisis data kualitatif merupakan upaya yang berlanjut, berulang dan terus-menerus sepanjang penelitian di lokasi hingga peneliti selesai dari lokasi penelitian. Setelah data diperoleh oleh peneliti selama melakukan penelitian (field reserch method), maka data tersebut diolah dan dianalisis secara kualitatif, mulai dari tahapan collection data, reduksi data dan display data (Usman dan P. S. Akbar, 2000). Kemudian memberikan penajaman tentang kebermaknaan hasil temuan penelitian. 


\section{HASIL DAN PEMBAHASAN}

\section{Pelaksanaan Supervisi Kepala Sekolah di SMK LPMD Adow}

Kepala Sekolah selaku pimpinan tertinggi memiliki tugas selaku supervisor yang bertugas untuk membina serta membantu Guru dalam meningkatkan kemampuan profesionalnya (Hazli dan R.R. Saputra, 2019). Supervisi Kepala Sekolah dalam di ini akan dibahas dari perencanaan, tahap pelaksanaan, dan upaya tindak lanjut.

Perencanaan program merupakan tahap awal dari suatu pekerjaan dalam melakukan supervisi. Perencanaan adalah proses memutuskan tujuan-tujuan apa yang akan dikejar selama suatu jangka waktu yang akan datang dan apa yang dilakukan agar tujuan itu dapat tercapai (Yusmadi, dkk 2012). Perencanaan program supervisi sangat penting agar terjaga rule yang disepakati. Supervisor (Kepala Sekolah) harus merencanakan program supervisi agar terciptanya tujuan supervisi yaitu membina Guru menjadi profesional, dan mewujudkan lulusan dan sekolah yang berkualitas.

Kepala Sekolah merencanakan program supervisi akademik diawali dengan menyusun tim supervisi. Tim supervisi yang dibentuk selanjutnya merumuskan tujuan supervisi akademik, menentukan sasaran supervisi akademik, dan membuat jadwal supervisi, serta mempelajari instrumen supervisi yang akan digunakan dalam melaksanakan supervisi kepada Guru. Tim supervisi membuat rumusan tujuan, sasaran, jadwal, dan instrumen pada program supervisi akademik. Instrumen tersebut akan menjadi dasar bagi Kepala Sekolah atau acuan pelakasanaan supervisi.

Supervisi Kepala Sekolah SMK LPMD Adow dilaksanakan seacara terorganisir dan terencana. Dikatakan terorganisir karena supervisi dilaksanakan bersama tim dan dikatakan terencana karena tim pelaksana menyusun perencanaan dengan sebaik-baiknya. Tim supervisi merencanakan bentuk kegiatan, menentukan sasaran, menentukan waktu dan menyusun instrumen.

Kepala Sekolah SMK LPMD Adow menyusun program supervisi akademik setiap tahun untuk dilaksanakan setiap semester. Tim supervisi akan merumuskan tujuan supervisi akademik, kemudian membuat jadwal dan mempelajari instrumen atau lembar pengamatan yang akan digunakan pada saat supervisi. Kepala Sekolah dan tim supervisi melaksanakan supervisi akademik dengan menggunakan instrument penilaian sebagai acuan untuk menilai kinerja Guru baik pada bidang administrasi maupun proses kegiatan belajar mengajar di dalam kelas. Pada bidang administrasi, aspek yang dinilai yaitu perangkat pembelajaran seperti program tahunan, program semester, silabus, RPP, dan penilaian. Sedangkan pada kegiatan proses belajar mengajar dinilai mulai dari kegiatan awal, kegiatan inti, dan kegiatan penutup.

Perencanaan supervisi dimaksudkan agar pelaksanaan kegiatan supervisor berjalan dengan lancar, efektif dan efisien. Langkah-langkah yang dilakukan dalam kegiatan perencanaan adalah: Pertama, penyusunan program-program supervisi, yaitu program semester dan bulanan semuanya termuat dalam program tahunan yang menjadi tanggung jawab masing-masing. Penyusunan program 
supervisi ini secara tidak langsung memberikan acuan dari pengawas dalam melaksanakan rencana kerja kepengawasan yang bersifat rencana kerja tahunan, semester dan bulanan. Kepala Sekolah SMK LPMD Adow dalam menjalankan tugas sebagai supervisor telah melaksanakan tahapan perencanaan supervisi dengan membentuk tim supervisi untuk membahas persiapan pelaksanaan supervisi seperti membuat instrument supervisi dan jadwal supervisi di kelas. Dalam penyusunan jadwal kunjungan di kelas, Kepala Sekolah merahasiakan dan Guru tidak pernah diberitahu jadwal pelaksanaan supervisi tersebut.

Pelaksanaan supervisi yang dilakukan Kepala Sekolah SMK LPMD Adow Kecamatan Pinolosian Tengah, yaitu menggunakan teknik dan pendekatan supervisi. Pendekatan supervisi yang diterapkan saat Kepala Sekolah melaksanakan supervisi akademik belum dicantumkan pada dokumen program supervisi akademik.

Pendekatan supervisi yang diterapkan di SMK LPMD Adow merupakan pendekatan kolaboratif, yang mengedepankan semangat kekeluargaan, dengan menekankan pada perbaikan kualitas mengajar, motivasi belajar dan kemauan bagi Guru untuk membua diri atas berbagai tantangan dan hambatan yang dihadapi. Setiap kunjungan kelas selesai dilaksanakan, Kepala Sekolah memberikan catatan kecil yang dituils pada buku kunjungan kelas milik Guru dan buku supervisi Kepala Sekolah. Hal ini digunakan untuk mengevaluasi kelemahan, membantu Guru dan melakukan perbaikan pada kinerja Guru.

Terkait dengan hasil supervisi, seringkali ditemukan kelalaian yang dilakukan Guru ketika mengajar, seperti banyak Guru yang belum menyiapkan silabus, rencana pelaksanaan pembelajaran (RPP), tidak menguasai materi yang sulit dan penggunaan media belajar yang masih kurang. Pelaksanaan supervisi di kelas memberikan gambaran nyata bahwa masih banyak kelemahan Guru ketika melaksanakan pembelajaran di kelas. Guru mengabaikan aspek perencanaan pembelajaran seperti silabus dan RPP. Akibatnya, Guru tidak menerapkan model dan atau metode pembelajaran inovatif yang dapat merangsang kemapuan berfikir siswa dan meningkatkan motivasi belajar sisiwa.

Usaha untuk membantu meningkatkan dan mengembangkan potensi sumber daya guna dapat dilaksanakan dengan berbagai alat dan tehnik supervisi. John Minor menjelaskan bahwa: Umumnya alat dan tehnik supervisi pendidikan dapat dibedakan dalam dua macam yaitu tehnik yang bersifat individual, yaitu tehnik yang dilaksanakan oleh seorang Guru secara individual dan tehnik yang bersifat kelompok, yaitu tehnik yang dilakukan untuk melayani lebih dari satu orang (Sahertian, P. A, 2008). Burhanuddin menyatakan pelaksanaan supervisi dila-kukan dalam tiga langkah kegiatan yaitu tahap pertemuan pendahuluan, tahap observasi kelas (Guru yang sedang mengajar dan tahap pertemuan balikan (Burhanuddin, 2017).

Sahertian mengemukakan bahwa: Observasi dan kunjungan kelas adalah tulang punggung supervisi. Pada tahap ini Guru mengajar di kelas dengan menerapkan komponen-komponen keterampilan yang telah disepakati pada pertemuan pendahuluan. Supervisor mengobservasi Guru 
dengan menggunakan instrumen observasi yang telah disepakati bersama. Di samping supervisor juga merekam secara objektif tingkah laku Guru dalam mengajar, tingkah laku siswa dalam belajar, dan interaksi Guru siswa dalam proses pembelajaran (Sahertian, P. A, 2008).

Supervisi terlaksana secara terprogram, terarah dan berkesinambungan. Oleh karena itu supervisi sangat perlu untuk ditindak lanjuti. Tindak lanjut dilakukan diantaranya dengan beberapa hal yaitu membimbing Guru dalam pelaksanaan kurikulum di SMK LPMD Adow, mengadakan pertemuan atau rapat, mengadakan diskusi kelompok dan mengadakan penataran-penataran.

Kepala Sekolah sebagai supervisor sangat memerhatikan kekurangan Guru. Kepala Sekolah selalu berusaha untuk memperbaiki kualitas mengajar Guru baik secara perorangan maupun secara bersama-sama. Hal tersebut dapat dilihat dari usaha Kepala Sekolah melaksanakan kegiatan bimtek bagi Guru dalam pembuatan media pembelajaran berbasis teknologi.

Jadi, Kepala Sekolah tidak memutuskan sendiri tindak lanjut atau program-program yang diperlukan sesuai dengan hasil analisis pelaksanaan supervisi. Kepala Sekolah mendiskusikan bersama dewan Guru dalam menentukan program yang relevan untuk diselenggarakan agar berbagai masalah yang ditemukan saat supervisi dapat teratasi.

Analisis hasil supervisi akademik dilakukan Kepala Sekolah bersama Guru dengan menganalisa secara bersama-sama hasil supervisi akademik yang dilaksanakan. Hal ini dibuktikan dengan adanya beberapa dokumen program yang direkomendasikan Kepala Sekolah, seperti kewajiban Guru mengikuti bimtek, workshop dan seminar-seminar yang berkaitan dengan peningkatan kopetensi pedagogik dan profesional Guru. Kepala Sekolah sewaktu melaksanakan supervisi atau observasi kelas, analisis dan evaluasi hasil supervisi akademik dilakukan antara Guru yang di supervisi dengan Kepala Sekolah. Kepala Sekolah dalam melakukan analisis hasil supervisi akademik dengan melibatkan Guru, kemudian secara bersama-sama mencari solusi terhadap masalah yang sifatnya umum sehingga masalah yang ada dapat terpecahkan. Bur-hanuddin bahwa: Supervisi adalah pembinaan yang diberikan kepada seluruh staf seko-lah agar mereka dapat mening-katkan kemampuan untuk mengem bangkan situasi pembelajaran yang lebih baik (Burhanuddin, 2017).

Setelah supervisi selesai dilaksanakan, dilanjutkan dengan tindak lanjut hasil supervisi terhadap Guru-Guru yang mengalami kesulitan dalam proses pem-belajaran. Dalam menindaklanjuti hasil supervisi, pengawas pengajaran dapat melakukan cara-cara pembinaan terhadap Guru yang mengalami kesulitan melalui diskusi, konferensi, home visit, tanya jawab dan melalui rapat-rapat dewan Guru, dan melakukan refferal ke pihak lain.

Supervisi Kepala Sekolah Meningkatan Motivasi dan kualitas mengajar Guru SMK LPMD Adow.

Supervisi Kepala Sekolah dapat meningkatkan kualitas mengajar Guru SMK LPMD Adow Kecamatan Pinolosian Tengah, Kabupaten Bolaang Mongondow Selatan. Supervisi Kepala Sekolah juga mendorong Guru untuk memperbaiki perencanaan pembelajaran. Para Guru harus merevisi 
penggunaan metode, model atau media pembelajaran ke arah yang lebih baik. Tuntutan teknologi yang terus berkembang pesat, turut mendorong perubahan dan pengembangan dalam teknologi pendidikan. Guru siap atau tidak siap harus inovatif menggunakan media pembelajaran yang relevan dan sesuai perkembangan zaman. Relevan berarti media yang digunakan dalam pembelajaran harus dapat menambah pemahaman siswa terhadap materi pembelajaran. Sesuai perkembangan zaman artinya bahwa media yang digunakan harus menggunakan teknologi terkini atau tenologi yang tidak ketinggalan zaman. Jadi, dapat dikatakan bahwa Supervisi Kepala Sekolah dapat memotivasi Guru untuk membuat perencanaan pembelajaran, dan meningkatkan kualitas perencanaan dan persiapan pembelajaran. Kualitas perencanaan pembelajaran selanjutnya dapat mendisposisi/menentukan kualitas pelaksanaan pembelajaran di kelas serta evaluasi dan penilaian hasil belajar siswa.

Supervisi kunjungan kelas yang dilakukan Kepala Sekolah dapat menjadi motivasi tersendiri untuk memacu Guru meningkatkan kompetensi pedagogik yaitu meningkatkan kualitas pembelajaran di kelas. Guru yang disupervisi di kelas termotivasi memperbaiki kualitas mengajarnya, apalagi setelah mendapat arahan dari Kepala Sekolah.

Dapat dimaknai bahwa pelaksanaan Supervisi Kepala Sekolah terhadap Guru berdampak pada kualitas mengajar Guru. Guru yang sudah melewati kegiatan supervisi berusaha melakukan perbaikan baik dari aspek administrasi, pelaksanaan pembelajaran dan evaluasi hasil belajar. Jadi semakin sering Kepala Sekolah berkunjung ke kelas untuk mensupervisi Guru maka kemampuan dan keterampilan melakukan kegiatan supervisi akademik semakin meningkat dan baik. Bagi Guru kunjungan kelas yang dilakukan Kepala Sekolah dapat menjadi motivasi tersendiri untuk memacu dirinya dalam meningkatkan kompetensi pedagogi dan prosesional yaitu meningkatkan kualitas pembelajaran di kelas yang berdampak pada peningkatan kualitas pendidikan di sekolah (Kadarwati, 2016). Hal ini sejalan dengan pendapat Jamal Ma'mur Ma'ruf Asmani bahwa supervisi bertujuan memberikan layanan dan bantuan untuk meningkatkan suasana belajar mengajar yang dilakukan Guru terhadap para siswa di kelas (Asmani, 2012). Kepala Sekolah selaku pimpinan tertinggi memiliki tugas selaku supervisor yang bertugas untuk membina serta membantu Guru dalam meningkatkan kemampuan profesional baik dirinya maupun Guru (Hazli dan R. R. Saputra, 2019). Berdasarkan hasil penelitian ini maka dapat dikatakan bahwa pelaksanaan supervisi kepala sekolah terbukti dapat meningkatkan motivasi dan kinerja guru. Untuk itu pelaksanaan supervisi kepala sekolah dapat selalu dilaksanaan dalam rangka mempertahankan sekaligus meningkatan motivasi dan kinerja guru. Dalam pelaksanaan supervisi kepala sekolah tentu saja perlu dilakukan perencanaan yang terstruktur dan dilaksanakan secara sistematis agar mampu menghasilkan proses supervisi yang baik. Dengan adanya pelaksanaan supervisi yang baik diharapkan akan dapat meningkatkan motivasi dan kinerja guru guna mendukung pencapaian tujuan pembelajaran yang lebih baik. Jadi supervise tidak hanya dilakukan untuk mencapai jumlah kunjungan yang ideal tetapi lebih kepada mendorong dan memotivasi guru dalam rangka meningkatkan kinerja. 


\section{KESIMPULAN DAN SARAN}

Pelaksanaan Supervisi Kepala Sekolah terhadap Guru di SMK LPMD Adow menggunakan pendekatan persuasif, yaitu suatu pendekatan dengan kekeluargaan. Dalam pendekatan ini, Kepala Sekolah lebih mengutamakan terciptanya kondisi harmonis antara kepa sekolah dengan segenap guru. Hal ini membuat Guru terbuka dalam menerima saran dan arahan dari Kepala Sekolah. Temuan hasil supervisi ditindaklanjuti dengan cara Kepala Sekolah memberikan saran secara personal kepada Guru untuk memperbaiki dan meningkatkan proses pembelajaran ke arah yang lebih baik. Supervisi Kepala Sekolah meningkatkan kualitas mengajar Guru di SMK LPMD Adow. Hal ini dirasakan langsung oleh guru, bahwa dengan dilakukannya supervisi, para guru termotivasi memperbaiki perencanaan pembelajaran, pelaksanaan pembelajaran di kelas, dan penilain hasil belajar serta kegiatan tindak lanjut. Dalam hal perencanaan pembelajaran, Guru berupaya membuat RPP dengan baik serta melakukan peninjauan secara berkala, dan memilih media dan metode pembelajaran yang tepat. Dalam hal pelaksanaan pembelajaran, guru berusaha menguasai materi pelajaran serta menyampaikan materi dengan sebaik-baiknya. Dalam hal penilaian, guru membuat instrumen dan pengukuran penilaian secara teliti. Dalam hal tindak lanjut, Guru melakukan kegiatan remiedial dan pengayaan bagi siswa yang belum mencapat standar Kriteria Ketuntasan Minimal (KKM).

Berdasarkan temuan penelitian, penelitian ini memberikan saran kepada berbagai pihak, diantaranya:

1. Bagi Kepala Sekolah agar dapat memperbaiki kualitas dan bahkan meningkatkan kualitas supervisi.

2. Bagi Guru, agar banyak bertanya dan terbuka mengenai proses perencanaaan, pelaksanaan dan tindak lanjut. Dengan banyak bertanya kita dapat memperoleh pengetahuan.

\section{DAFTAR PUSTAKA}

Asmani, JM (2012). Tips AplikasiManajemen Sekolah. Jogyakarta: Diva Pres, 2012.

As-Suwaidan, T. Muhammad \& F. U. Basyarahil (2009). Memproduksi Pemimpin Hebat. Surabaya: Pustaka Yassir.

Burhanuddin, Soetopo, H., Imron, A., Maisyaroh, dan Ulfatin, N (2017). Supervisi Pendidikan dan engajaran: Konsep, Pendekatan, dan Penerapan Pembinaan Profesional. Malang: Fakultas lmu Pendidikan Universitas Negeri Malang.

Firdausi, Annas (2018). Pengaruh Supervisi Dan Kepercayaan Diri Terhadap Kepuasan Kerja Guru SMKN Di Jakarta Timur. Jurnal Sap Vol. 2 No. 3 April 2018, hlm.270-278.

Glanz, Jeffrey dan S. Susan (2000). Supervision in Practice. California: Corwin Press,Inc. Glickman. 
Hazli dan R. R. Saputra (2019). Analisis Pengaruh Supervisi Pengawas Dan Supervisi Kepala Sekolah Terhadap Kinerja Guru Di Madrasah Ibtidaiyah Kecamatan Sukau Lampung Barat. Jurnal Publikasi Pendidikan | Volume 9 Nomor 1, Februari 2019, hlm. 62-68. https://doi.org/10.26858/publikan.v11i1.16394

Kadarwati, A (2016). Peningkatan Kualitas Pembelajaran Melalui Supervisi Akademikdengan Teknik Kunjungan Kelas. Gulawentah: Jurnal Studi Sosial, Volume 1 Nomor 2 Desember 2016), h. 103-120.

Makawimbang, Jerry H (2011). Supervisi dan Peningkatan Mutu Pendidikan. Bandung: Alfabeta. Mulyasa, E (2015). Manajemen dan Kepemimpinan Kepala Sekolah (Cet. Ke-5 . Jakarta: Bumi Aksara.

Nasution (2006). Metode Penelitian (Cet. I). Jakarta: Bina Rupa Aksara.

Nawawi, Hadari (1988). Administrasi Pendidikan. Jakarta: CV. Haji Mas Agung.

Neagley, R.L. dan Evans D.N (1980). Handbook for effective supervision of instruction (Third Edition). Englewood Cliffs, New Jersey: Prentice-Hall, Inc.

Piet. A. Sahertian dan F. Mataheru (2000). Konsep Dasar dan Teknik: Supervisi Pendidikan (Dalam Rangka Pengembangan Sumber Daya Manusia). Jakarta: Rineka Cipta.

Sarifudin (2019). Implementasi Supervisi Kepala Sekolah Terhadap Kinerja Guru Dalam Upaya

Meningkatkan Kualitas Pembelajaran, Di Madrasah Ibtidaiyah Negeri (Min) Kota

Bogor. Islamic Management: Jurnal Manajemen Pendidikan Islam, Vol. 02, No. 01, Januari 2019， hlm. 49-70. DOI: http://dx.doi.org/10.30868/im.v2i01.374

Soetjipto dan Kosasi (1999). Profesi Keguruan. Jakarta: Rineka Cipta.

Suhardan, Dadang (2010). Supervisi Profesional, Layanan Dalam Meningkatkan Mutu Pembelajaran Di Era Otonomi Daerah (Cet. II). Bandung: Alfabeta, 2010.

Surasni (2018). Pengaruh Supervisi, Kepemimpinan Partisipatif Dan Kepuasan Kerja Terhadap Kualitas Kerja Guru Sma Di Jakarta Selatan. PEKOBIS Jurnal Pendidikan, Ekonomi dan Bisnis, Vol 1 No. V, Mei 2018, hlm. 26-41.

DOI: http://dx.doi.org/10.32493/pekobis.v1i5.P\%25p.1229

Usman, H dan P. S. Akbar (2000). Metodologi Penelitian Sosial. Jakarta: Bumi Aksara.

Yusmadi, dkk (2012). Pelaksanaan Supervisi Pendidikan Pada Madrasah Aliyah Negeri 1 Sigli. Jurnal Administrasi Pendidikan, Pascasarjana Universitas Syiah Kuala, Volume 1, No. 1, Agustus 2012, hlm. 82- 95. 